\title{
Iodination of aromatic and heteroaromatic compounds in the presence of iodine and hydrogen peroxide in water: A balance between atom economy and high yields.
}

\author{
Rafael D. C. Gallo, Irlon M. Ferreira, Gleison A. Casagrande, \\ Lucas Pizzuti and Cristiano Raminelli*
}

Faculdade de Ciências Exatas e Tecnologia, Universidade Federal da Grande Dourados, Dourados, MS, Brazil

*e-mail address: raminelli@ufgd.edu.br

Keywords: iodination reaction, iodinated compounds, reaction in water

\section{INTRODUCTION}

Recently we published a work involving the efficient and selective diiodination of phenols using $\mathrm{I}_{2}$ and $\mathrm{H}_{2} \mathrm{O}_{2} 30 \%$ in water. ${ }^{1}$ Afterwards, we decided to subject aromatic and heteroaromatic compounds to the same reaction conditions, performing a balance between the amounts of the reagents and the yields obtained, aiming to the formation of interesting iodinated molecules in high yields.

\section{RESULTS AND DISCUSSION}

We treated phenol (1a) with 1.5 equiv. of $\mathrm{I}_{2}$ and 3 equiv. of $\mathrm{H}_{2} \mathrm{O}_{2} 30 \%$ in water at $50{ }^{\circ} \mathrm{C}$ for $24 \mathrm{~h}$ and obtained 2,4,6-triiodophenol (2a) in a moderate yield of $65 \%$ (Table 1, entry 1 ). In the attempt of increasing this yield, we used 2 equiv. of $\mathrm{I}_{2}$ and 4 equiv. of $\mathrm{H}_{2} \mathrm{O}_{2} 30 \%$ producing the triiodinated phenol $2 \mathbf{a}$ in a yield of $83 \%$ (entry 2). The aromatic compound $\mathbf{1 b}$ and the heteroaromatic compound $\mathbf{1 c}$ were subjected to the reaction with 2 equiv. of $I_{2}$ and 4 equiv. of $\mathrm{H}_{2} \mathrm{O}_{2} 30 \%$ resulting in the triiodinated products $\mathbf{2 b}$ and $\mathbf{2 c}$, respectively, in good yields (entries 3 and 4). The balance between amounts of the reagents and yields obtained was extended for reactions of diiodination (entries 6 to 9) and for reactions of monoiodination (entries 10 to 15). In general, diiodinated and monoiodinated aromatic and heteroaromatic compounds were produced in considerable yields.

\section{CONCLUSION}

A balance between amounts of the reagents and the yields obtained was carried out for the reaction of iodination of aromatic organic compounds using $\mathrm{I}_{2}$ and $\mathrm{H}_{2} \mathrm{O}_{2} 30 \%$ in water at $50{ }^{\circ} \mathrm{C}$ and interesting iodinated molecules were produced in good yields.

\section{ACKNOWLEDGEMENTS}

We thank CNPq and FUNDECT for support.

\section{REFERENCES}

${ }^{1}$ Gallo, R. D. C.; Gebara, K. S.; Muzzi, R. M.; Raminelli, C. J. Braz. Chem. Soc. 2010, 21, 770-774.
Table 1. Synthesis of iodinated aromatic and heteroaromatic compounds (2). ${ }^{a}$

(I)

